\title{
Smoking, use of oral contraceptives, and medical induction of remission were risk factors for relapse in Crohn's disease
}

\author{
Timmer A, Sutherland LR, Martin F, and the Canadian Mesalamine for Remission of Crohn's Disease Study Group. Oral \\ contraceptive use and smoking are risk factors for relapse in Crohn's disease. Gastroenterology 1998 \\ fun;114:1143-50.
}

\section{Question}

What are the risk factors for relapse in patients with Crohn's disease in remission?

\section{Design}

48 week study of patients in the placebo group of a randomised controlled trial.

\section{Setting}

31 clinical centres in Canada.

\section{Patients}

152 patients (median age 34 y, 58\% women) who were $18-82$ years of age; had Crohn's disease with $\geqslant 2$ exacerbations in the previous 4 years and 1 exacerbation or surgical resection in the previous 18 months; were in remission (Crohn's Disease Activity Index $\leqslant 150$ ); and had not received treatment with corticosteroids for $\geqslant 30$ days, immunosuppressants for $\geqslant 90$ days, and mesalazine or metronidazole for 7 days before study entry. Exclusion criteria were a history of proctocolectomy or malignant disease, short bowel syndrome, $>3$ bowel resections in the previous 10 years, chronic perianal disease, drug abuse, or major illness.

\section{Assessment of risk factors}

Smoking, use of oral contraceptives, disease location and duration, age at diagnosis, time in remission, recent resection, history of blood transfusions, baseline disease activity, and quality of life were assessed in personal interviews.

\section{Main outcome measure Relapse.}

\section{Main results}

61 patients relapsed, 60 patients remained in remission, and 31 patients were withdrawn without relapse. Relapses occurred more frequently in women than in men $(46 \% v$ $33 \%, \mathrm{p}=0.05$ ) and in patients who achieved remission after medical treatment than after surgery $(46 \%$ v $25 \%$, $\mathrm{p}=0.02)$. Relapse was also associated with smoking status (current smokers 53\%, former smokers 35\%, non-smokers $30 \% ; \mathrm{p}=0.02$ ) and oral contraceptive use (current use $43 \%$, previous use $70 \%$, no use $27 \%$; $<<0.001$ ). Multivariate analysis showed that an increased risk of relapse was associated with current smoking, previous or current oral contraceptive use, and medical induction of remission; sex and previous smoking were not associated with an increased risk of relapse (table). No interaction between smoking and oral contraceptive use occurred.

\section{Conclusion}

Current smoking, previous or current oral contraceptive use, and medical induction of remission were independent risk factors for relapse in patients with Crohn's disease in remission.

Source of funding: German Academic Exchange Service.

For correspondence: $\operatorname{Dr} L \mathrm{R}$ Sutherland, Department of Community Health Sciences, University of Calgary, 3300 Hospital Drive Northwest, Calgary, AB T2N 4N1, Canada. FAX +14032707307.

Risk factors for relapse in remission of Crohn's disease

\begin{tabular}{ll}
\hline Risk factor & Adjusted $H R^{\star}(95 \%$ CI $)$ \\
\hline Men $v$ women & $0.8(0.4$ to 1.6$) \dagger$ \\
Medical $v$ surgical induction of remission & $2.1(1.0$ to 4.2$)$ \\
Current $v$ never smoking & $2.1(1.1$ to 4.2$)$ \\
Previous $v$ never smoking & $1.0(0.5$ to 2.0$) \dagger$ \\
Ever $v$ never use of oral contraceptives & $3.0(1.5$ to 5.9$)$ \\
\hline
\end{tabular}

${ }^{\star} \mathrm{HR}=$ hazard ratio, which was adjusted for sex, type of induction of remission, smoking status, and oral contraceptive use.

†Not significant.

\section{Commentary}

Epidemiological studies reporting positive associations between smoking and oral contraceptives (OC) and Crohn's disease first appeared in the mid-1980s. Subsequently neither association has been found to be especially strong (relative risks around 3 for smoking and 2 for $\mathrm{OC}$ ) and there continues to be uncertainty as to whether or not these are causal associations. ${ }^{1}$ Smoking and OC use also confound one another, with OC use being more common in smokers.

In contrast to the association between Helicobacter pylori and duodenal ulcer, it is not possible to test the reversibility of the associations by randomised trials. A less rigorous test of causation is to observe the relations between these factors and prognosis of Crohn's disease as Timmer et al have done. Examining prognosis in the context of a controlled trial has several attractions-prospective data recording, minimal problems of misclassification and unbiased assessment of outcome.

Their twofold increase in relapse rate for current smokers is consistent with earlier retrospective studies. The relapse rate is less well-established in ex-smokers. Ret- rospective assessment of ex-smoking presents obvious difficulties. The one previous prospective study involved only 23 ex-smokers and found rates similar to never smokers. ${ }^{2}$ Timmer et al's identical finding not only strengthens the evidence of reversibility but should buttress our efforts to persuade smokers with Crohn's disease to stop. ${ }^{3}$ Although their findings on smoking are reassuring and unlikely to excite debate, the OC use results are much less clear cut and likely to be controversial. The total number of women is modest $(88$ women) and the decision to restrict 
(commentary continued from page 311) analysis to women aged $18-55$ reduces the numbers further. Including all the patients randomised (to mesalazine as well as placebo) would have increased the numbers but as there was a statistically significant interaction between treatment and $\mathrm{OC}$ use they were unable to do this.

The threefold increase in the relapse rate of OC users is predominantly accounted for by a high rate in ex-users which is much greater than the rate in current users, which alone was not statistically significant. Indeed, figure 2 shows that the univariate relapse rate at 48 weeks in their 17 ex-OC users was $>70 \%$ compared with $<50 \%$ in 28 current OC users and $<30 \%$ in 30 never users. It is implausible that a causal relation should be stronger in ex-users than current users. Furthermore, ex-use is not described so it is unclear what proportion have not taken OC for several years. In the two British cohort studies of OC use ex-users had the same risk of Crohn's disease as never users. ${ }^{4}$

Clearly, more data are needed, possibly from other trials of maintenance treatment. As yet, there is insufficient evidence to advise patients with Crohn's disease to stop taking OC but if asked, advice not to start taking OC might be prudent.

R F A LOGAN

Dept of Public Health and Epidemiology,

University of Nottingham Medical School,

Queen's Medical Centre,
Clifton Boulevard,

Nottingham NG7 2UH, UK

1 Logan RFA. Epidemiology - Smoking and oral contraception. In: Allan RN, Keighley M, Alexander-Williams et al, eds. Inflammatory bowel disease. 3rd edn. London: Churchill Livingstone, 1996:47-52.

2 Duffy LC, Zielezny MA, Marshall JR, et al. Cigarette smoking and risk of clinical relapse in patients with Crohn's disease. Am f Prev Med 1990;6:161-6.

3 Low-Beer TS, Shields PL. Patients' awareness of adverse relation between Crohn's disease and their smoking: questionnaire survey. BMF 1996; 313:265-6.

4 Kay CR, Logan RFA. Oral contraception, smoking and inflammatory bowel diseasefindings in the Royal College of General Practitioners Oral Contraception Study. Int $\mathcal{f}$ Epidemiol 1989;18:105-7. 